\title{
Management of severe head injury with brain exposure in three loggerhead sea turtles Caretta caretta
}

\author{
D. Franchini ${ }^{1, *}$, L. Cavaliere ${ }^{1}$, C. Valastro ${ }^{1}$, F. Carnevali ${ }^{2}$, A. van der Esch ${ }^{2}$, O. Lai ${ }^{1}$, \\ A. Di Bello ${ }^{1}$ \\ ${ }^{1}$ Department of Veterinary Medicine, Bari University, \\ Strada Provinciale per Casamassima km 3, 70010 Valenzano (Ba), Italy \\ ${ }^{2}$ Energy and Sustainable Economic Development (ENEA), Casaccia Research Centre, Via Anguillarese 301, 00123 Rome, Italy
}

\begin{abstract}
The loggerhead Caretta caretta is the most common sea turtle in the Mediterranean. Currently, sea turtles are considered endangered, mainly due to the impact of human activities. Among traumatic lesions, those involving the skull, if complicated by brain exposure, are often life-threatening. In these cases, death could be the outcome of direct trauma of the cerebral tissue or of secondary meningoencephalitis. This uncontrolled study aims to evaluate the use of a plantderived dressing (1 Primary Wound Dressing ${ }^{\circledR}$ ) in 3 sea turtles with severe lesions of the skull exposing the brain. Following surgical curettage, the treatment protocol involved exclusive use of the plant-derived dressing applied on the wound surface as the primary dressing, daily for the first month and then every other day until the end of treatment. The wound and peri-wound skin were covered with a simple secondary dressing without any active compound (non-woven gauze with petroleum jelly). Data presented herein show an excellent healing process in all 3 cases and no side effects due to contact of the medication with the cerebral tissue.
\end{abstract}

KEY WORDS: Wound healing $\cdot$ Dressing $\cdot$ Skull fracture $\cdot$ Brain injury $\cdot$ Trauma $\cdot$ Chelonid

Resale or republication not permitted without written consent of the publisher

\section{INTRODUCTION}

Sea turtles are considered endangered because of their vulnerability to anthropogenic effects (Lutcavage et al. 1997). Nearly all species of sea turtle are classified as threatened in the IUCN's Red List of Threatened Species (www.iucnredlist.org, accessed 16 Nov 2015). Human activities, including boating and fishing, can be associated with traumatic injuries to sea turtles including propeller wounds and blunt force trauma from impact with watercraft or fishing gear. Turtles with boat-strike injuries present severe fractures of the carapace, plastron and skull; flipper lacerations; and injuries of the underlying soft tissue. Moreover, fishermen may deliberately traumatize sea turtles presumed to have diminished the catch or damaged gear (Lutcavage et al. 1997, McArthur et al. 2004). Severe traumatic lesions, mainly penetrating the lungs and kidneys, are a common cause of injury and death among sea turtles (Orós et al. 2005). Severe head injury can cause brain damage (Naganobu et al. 2000). If the sea turtle survives, weakness, disorientation and irreversible deficits may ensue, hindering the turtle's ability to feed or escape from predators (Goldberg et al. 2010). Early diagnosis and treatment of sea turtles with head trauma improves the morbidity and mortality rates associated with any intracranial injury (Oertel et al. 2002), but the majority of sea turtles with a head injury do not come under the observation of rehabilitation centers immediately after the trauma. Moreover, owing to the severity of the head injuries, for 
many turtles presented to rehabilitation centers, the most humane course of action is euthanasia (Goldberg et al. 2010). Topical dressings are routinely used to manage reptile wounds by limiting opportunistic infections and facilitating the healing response. Unfortunately, not all topical dressings are beneficial (Mitchell \& Diaz-Figueroa 2004, Rinaldi et al. 2013). To the authors' knowledge, no topical medications for head trauma with brain exposure are currently described in the literature for sea turtles.

Research on natural substances at the Energy and Sustainable Economic Development Research Centre of Casaccia, Italy, has led to the formulation of a novel primary dressing for wound management based on a mixture of St. John's wort Hypericum perforatum oil and neem Azadirachta indica oil. The dressing is designed to create a moist wound-healing environment, and the oil layer prevents the secondary dressing from adhering to the wound (Läuchli 2012, Carnevali et al. 2014). It has an antimicrobial effect (Desbois \& Smith 2010) because of its combination of saturated, mono-unsaturated and polyunsaturated free fatty acids, which possess antimicrobial properties, thereby dispensing with the need to use antimicrobials/disinfectants and promoting the regeneration of the epidermis (van der Esch et al. 2007, Läuchli 2012, Läuchli et al. 2012, Mainetti \& Carnevali 2013).

This uncontrolled study aims to describe the clinical results obtained in the treatment of 3 loggerhead turtles with severe head trauma exposing the brain using the plant-derived dressing one Vet (1 Primary Wound Dressing ${ }^{\circledR}$, Phytoceuticals AG) as the primary wound dressing and dispensing with any other topical disinfectant/antimicrobial devices.

\section{MATERIALS AND METHODS}

Between January 2013 and July 2014， 3 loggerhead sea turtles Caretta caretta were referred to the Surgery Section at the Department of Veterinary Medicine in Bari (Italy) after having been taken to local Adriatic Sea turtle rescue centers because of severe depressed skull fractures. The animals, having been found either drifting at sea or stranded along the coasts, were referred to rescue centers by volunteers.

On admission, the sea turtles were measured and underwent a complete physical examination; curved carapace length from notch to tip ranged from 61.0 to $65.1 \mathrm{~cm}$ (mean $62.66 \mathrm{~cm}$ ), curved carapace width was 54.2 to $60.1 \mathrm{~cm}$ (mean $58.83 \mathrm{~cm}$ ), and weight was
21.6 to $26.5 \mathrm{~kg}$ (mean $24.03 \mathrm{~kg}$ ). The animals were in poor condition, emaciated and malnourished. Clinical signs included dehydration, prostration, anorexia and apathy.

Bone fragments, when present, pointed inward towards the brain, characterizing a penetrating head injury (Turtles A and C). The frontoparietal, frontal, prefrontal, supraocular, temporal (in all cases) and postorbital (Turtle $\mathrm{A}$ and $\mathrm{C}$ ) bone plates were severely damaged or completely missing.

A neurologic examination was performed to evaluate neurological deficits. General activity; neck, front flipper and rear flipper movements; and pupillary, eyelid and cloacal reflexes were observed. Turtles B and $\mathrm{C}$ did not show any neurological abnormality, while Turtle A showed areflexia of the right limbs and a diminished right eyelid reaction.

Initial treatments included rehydration with lactated Ringer's solution and saline solution $\left(20 \mathrm{ml} \mathrm{kg}^{-1}\right.$ $\mathrm{d}^{-1}$, through the intracoelomic route via the inguinal fossa) (Camacho et al. 2015), enrofloxacin (Baytril $5 \%$, Bayer; $5 \mathrm{mg} \mathrm{kg}^{-1}$ intramuscularly [IM] after dilution 1:4 in $\mathrm{NaCl}$ solution $0.9 \%$, every $24 \mathrm{~h}$ ) (Mader \& Divers 2013) and tramadol (Altadol, Formevet; 2 to $4 \mathrm{mg} \mathrm{kg}^{-1} \mathrm{IM}$, every $48 \mathrm{~h}$ ), and the turtles were hospitalized in rooms with temperatures between 25 and $28^{\circ} \mathrm{C}$. The wound was cleaned and flushed with sterile saline, foreign debris was carefully removed from the fracture site, and sampling from the lesions for microbiological culture was carried out.

A radiographic study of the sea turtles' skulls was performed and showed fractures of the frontal and parietal bone in all turtles, postorbital bone in Turtles $\mathrm{A}$ and $\mathrm{C}$ and prefrontal bone in Turtle A. Dorso-ventral (vertical beam), lateral and cranio-caudal (horizontal beam) radiographs were also taken to evaluate the lungs, since respiratory disease is common in chelonians, and to evaluate the digestive system to rule out the presence of foreign objects such as hooks and/or fishing lines (McArthur et al. 2004).

A computed tomography (CT) scan of the head in 2 animals (Turtles A and B) was performed to better characterize the lesion and evaluate the full extent of the damage. CT scans were obtained with a helical 16-slice CT scanner (LightSpeed 16, GE Medical Systems). The slice thickness was set at $2 \mathrm{~mm}$ at $120 \mathrm{kV}$, $1 \mathrm{~s}$ scanning and $150 \mathrm{~mA}$. The images were then submitted to 3D and multi-planar reconstruction (OsiriX, Pixmeo Sàrl).

Evaluation of the CT images revealed the presence of comminuted fractures of the parietal, postorbital (except for Turtle B), prefrontal (Turtle A) and frontal bones; in Turtle A, some of the fragments appeared 

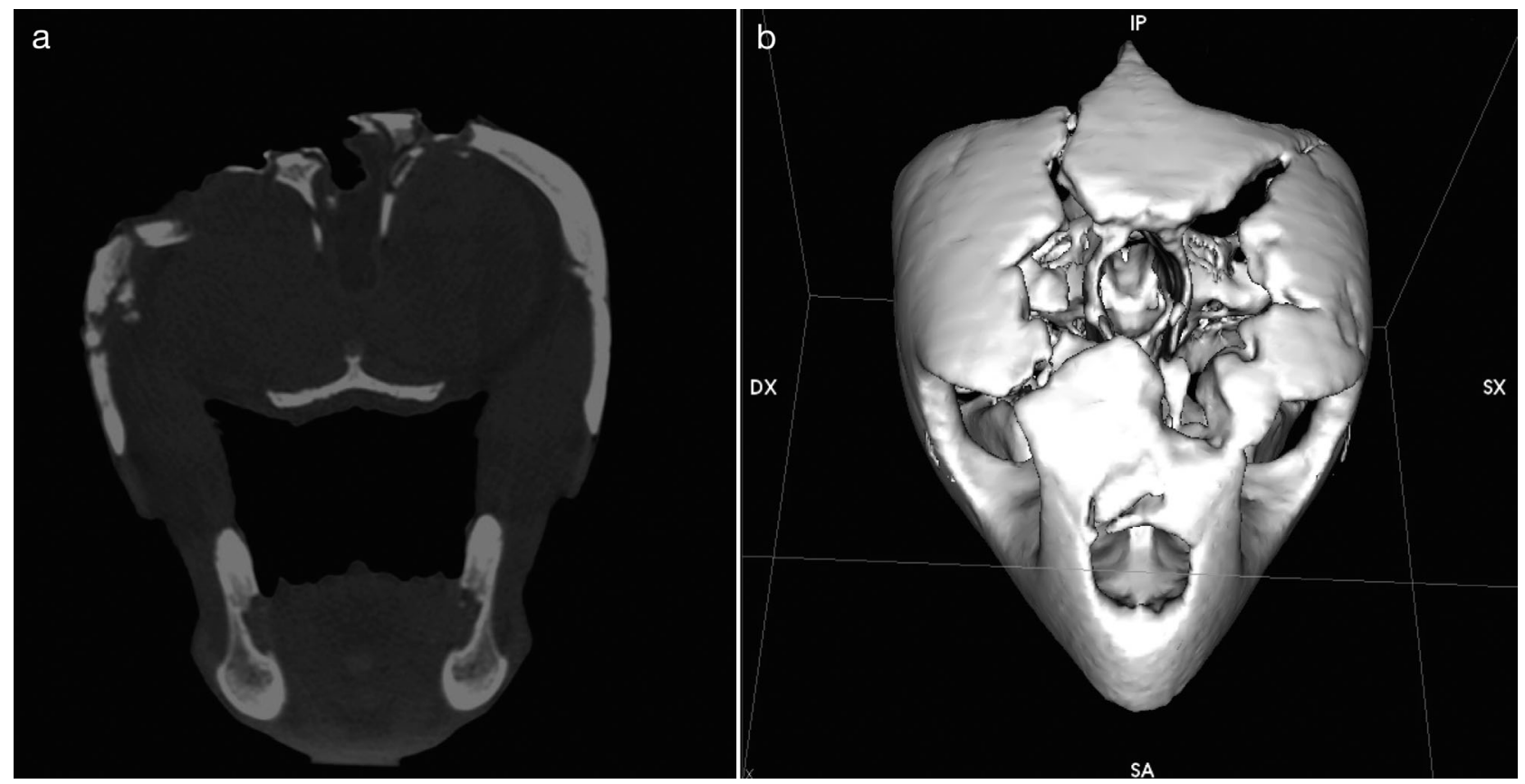

Fig. 1. Turtle A. (a) Computed tomography (CT) (brain algorithm: window width 40, window level 400) transverse image showing the presence of a brain trauma injury and comminuted fractures of the parietal, prefrontal and frontal bones; some of the fragments appear inverted toward the damaged dura. Pneumocephalus and lacerations of the brain tissue are present. (b) 3D CT bone imaging. Note the extent of the skull injuries

inverted toward the disrupted dura, and pneumocephalus and cerebral lacerations and cerebral swelling were detected. Portions of the adductor muscles of the jaw, pseudotemporal, dorsal and ventral pterygoid were lacerated.

The lesions were mostly lithic with no formation of new bone tissue. In addition, in Turtle A, the left ocular globe was slightly shifted downward due to the pressure of the surrounding tissues, and caudally, another fracture line became evident at the left zygomatic and postorbital bones (Fig. 1).

The turtles underwent anesthesia for debridement and curettage of the skull wounds, and an esophagostomy tube (Di Bello et al. 2011) was started on the 3rd day because they were unable to eat by themselves.

Medetomidine (50 $\mathrm{gg} \mathrm{kg}^{-1}$, Domitor, Pfizer) was administered intravenously in the cervical venous sinus as a preanesthetic, and after $20 \mathrm{~min}$, anesthesia was induced with 3.0 to $5.0 \mathrm{mg} \mathrm{kg} \mathrm{g}^{-1}$ intravenous propofol (Proposure, Merial). A 6 or $7 \mathrm{~mm}$ diameter uncuffed endotracheal tube was used for tracheal intubation, and anesthesia was maintained with oxygen and sevoflurane 2 to $3 \%$ (SevoFlo, Esteve) throughout the surgery. A non-rebreathing circuit and manual ventilation were used, with 10 to 15 breaths $\mathrm{min}^{-1}$ until a surgical anesthetic plane was achieved and thereafter at 3 to 5 breaths min $^{-1}$ during maintenance anesthesia. Anesthesia was monitored by electrocardiography and capnography.

A catheter was placed in the cephalic vein (Di Bello et al. 2010), and lactated Ringer's solution and $0.9 \%$ $\mathrm{NaCl}$ (1:1) were administered at $2 \mathrm{ml} \mathrm{kg}^{-1} \mathrm{~h}^{-1}$.

At $15 \mathrm{~min}$ before the scheduled end of the surgery, the anesthetic was discontinued, and at the end of the surgery, $200 \mathrm{\mu g} \mathrm{kg}^{-1}$ intramuscular atipamezole (Antisedan, Pfizer) was administered to aid recovery from anesthesia. Passive ventilation at awakening was 2 breaths $\mathrm{min}^{-1}$.

After the placement of a feeding tube, the turtles were placed in ventral recumbency, a swab for microbial evaluation of the wound was taken, and then the wound was debrided to remove necrotic tissue and bone fragments. In all cases, the fractures were so deep that the brain tissue was exposed. Following surgical curettage, the treatment protocol included rinsing of the wound with sterile saline and the exclusive use of the plant-derived dressing 1 Primary Wound Dressing ${ }^{\circledR}$ applied on the wound surface as a primary dressing, daily for the first month and then every other day until the end of treatment. The primary dressing was applied in a thin layer directly on the wound as a spray or by means of a brush (Fig. 2). Non-woven gauzes impregnated with 

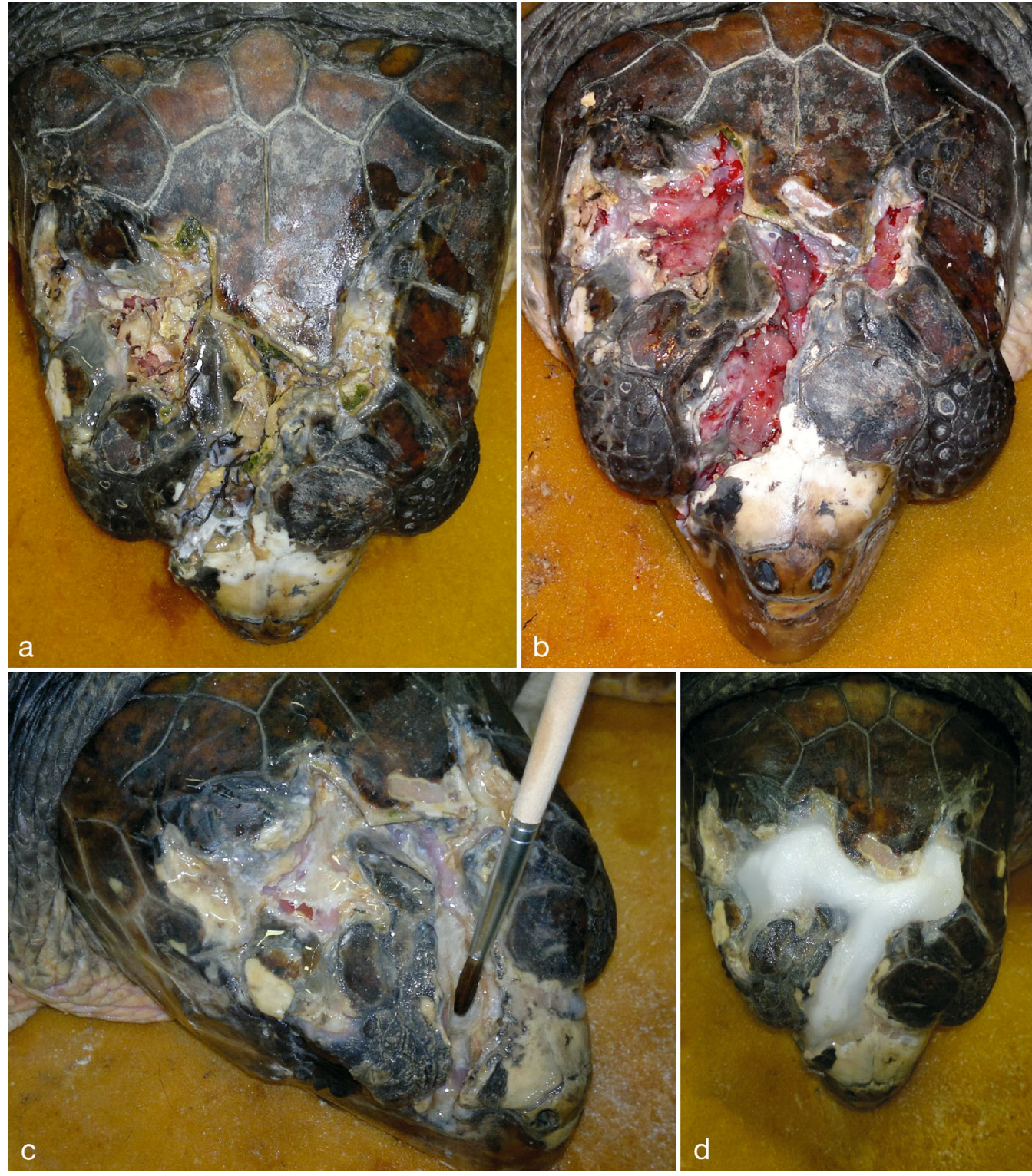

Fig. 2. Turtle A. Appearance of the wound on arrival at the clinic (Day 1) (a) before and (b) after the surgical curettage. (c) Wound on Day 30 while applying 1 Primary Wound Dressing ${ }^{\circledR}$ using a nontraumatic brush. (d) Appearance of the wound after the end of the medication. Note the layer of Vaseline to waterproof the underlying tissues petroleum jelly (without any active compound) were used as a simple secondary dressing directly on the wound and peri-wound tissues. The gauzes were inserted in the depression created by the traumatic injury to obtain a waterproof environment and allow the medicament to act without being washed out once the animal was placed in water. The animals continued the antibiotic therapy with enrofloxacin (Baytril 5\%, $5 \mathrm{mg} \mathrm{kg}^{-1} \mathrm{IM}$ after dilution 1:4 in $\mathrm{NaCl}$ solution $0.9 \%$, every $24 \mathrm{~h}$ ) for $2 \mathrm{wk}$ and tramadol (Altadol, 2 to $4 \mathrm{mg} \mathrm{kg}^{-1} \mathrm{IM}$, every $48 \mathrm{~h}$ ) for $5 \mathrm{~d}$, after surgical debridement (Fig. 2).

During the $24 \mathrm{~h}$ following surgery, each turtle was kept wrapped with damp cloths in a few centimeters of warm water. By the second day, the sea turtles could swim easily when dipped into a tank containing water at a controlled temperature (always 25 to $28^{\circ} \mathrm{C}$ ).

Healing times and any adverse reactions were monitored. After the closure of the lesion on Turtle B, a CT scan was performed to check the condition of the skull and the brain (see Fig. 4).

Parameters such as the initial wound area (IWA) $\left(\mathrm{cm}^{2}\right)$ and time to heal (TTH) (d), defined as the time from the first visit until complete re-epithelialization, were recorded. These data were used to calculate the proliferation rate $\left(\mathrm{cm} \mathrm{d}^{-1}\right)$, defined as the relationship between IWA and TTH. To record the IWA, the size and appearance of the wound surface were photographed using a digital camera. The wound areas 


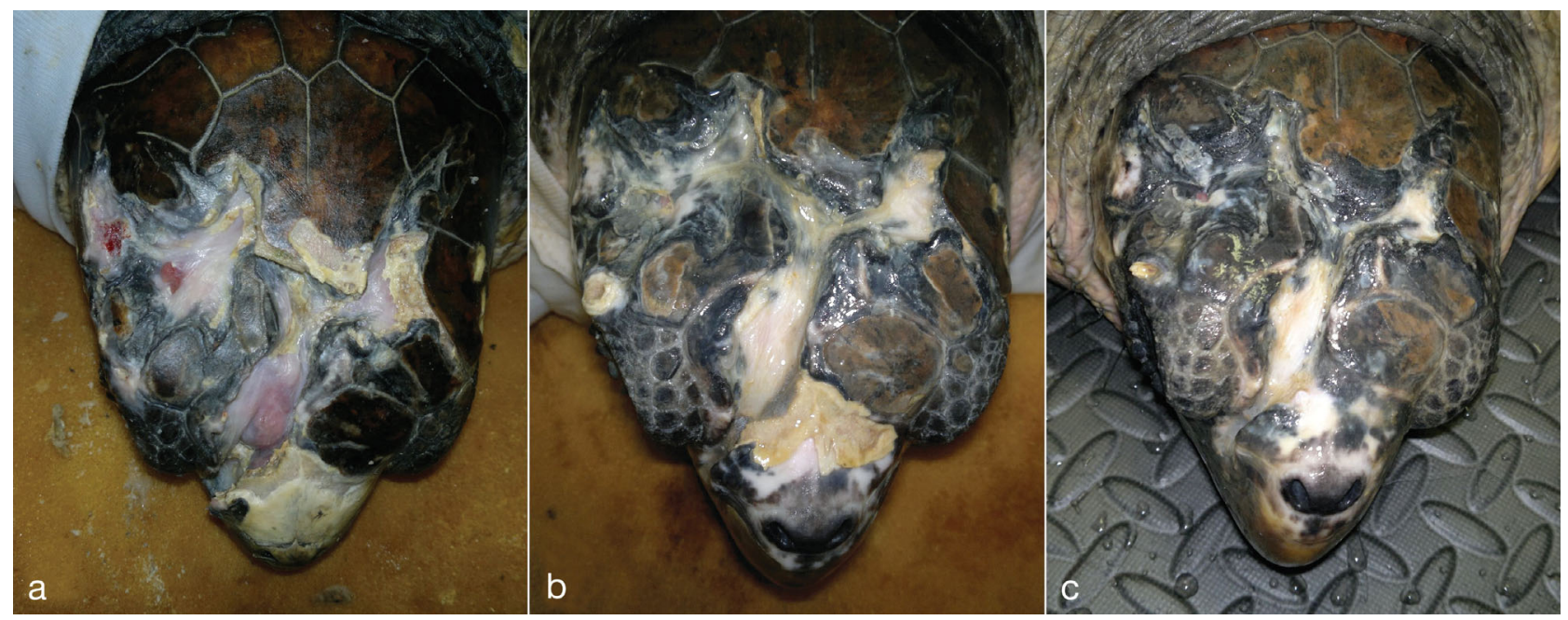

Fig. 3. Turtle A. (a) Appearance of the wound on Day 25 after the surgical curettage. Aspect of the wound after healing was completed (b) on Day 60 and (c) on Day 104 at discharge at the sea turtle rescue center

$\left(\mathrm{cm}^{2}\right)$ were calculated using commercially available software (CAD-CAM Autodesk MAP 3D, 2005).

The esophagostomy tube was removed only after the turtles had started to feed spontaneously. A neurological examination was repeated during and at the end of treatment to exclude potential induced neurotoxicity.

\section{RESULTS}

Swabs taken from the skull lesions showed the presence of Pseudomonas sp., Proteus sp. and Enterobacter sp. Daily dressing was carried out without any apparent sign of procedural discomfort. It was easy and quick to apply, and the animals showed little or no reaction during the first dressings, and after only 2 to 3 applications of 1 Primary Wound Dressing ${ }^{\circledR}$, no reaction at all was elicited. The secondary dressing did not stick to the wound surface, and daily removal never damaged the wound bed.

All 3 bone defects were completely healed by secondary intention; only Turtle A required an additional surgical curettage. The mean size of the bone defect on presentation (IWA) was $28.5 \pm 4.5 \mathrm{~cm}^{2}$ (range from $24 \mathrm{~cm}^{2}$ in Turtle C to $33 \mathrm{~cm}^{2}$ in Turtle A). The mean treatment period until total re-epithelialization of the wounds (TTH) was $75.5 \pm 9.5 \mathrm{~d}$ (ranging from a minimum of $66 \mathrm{~d}$ in Turtle $\mathrm{A}$ to a maximum of $85 \mathrm{~d}$ in Turtle B) (Figs. 3 \& 4). The proliferation rate

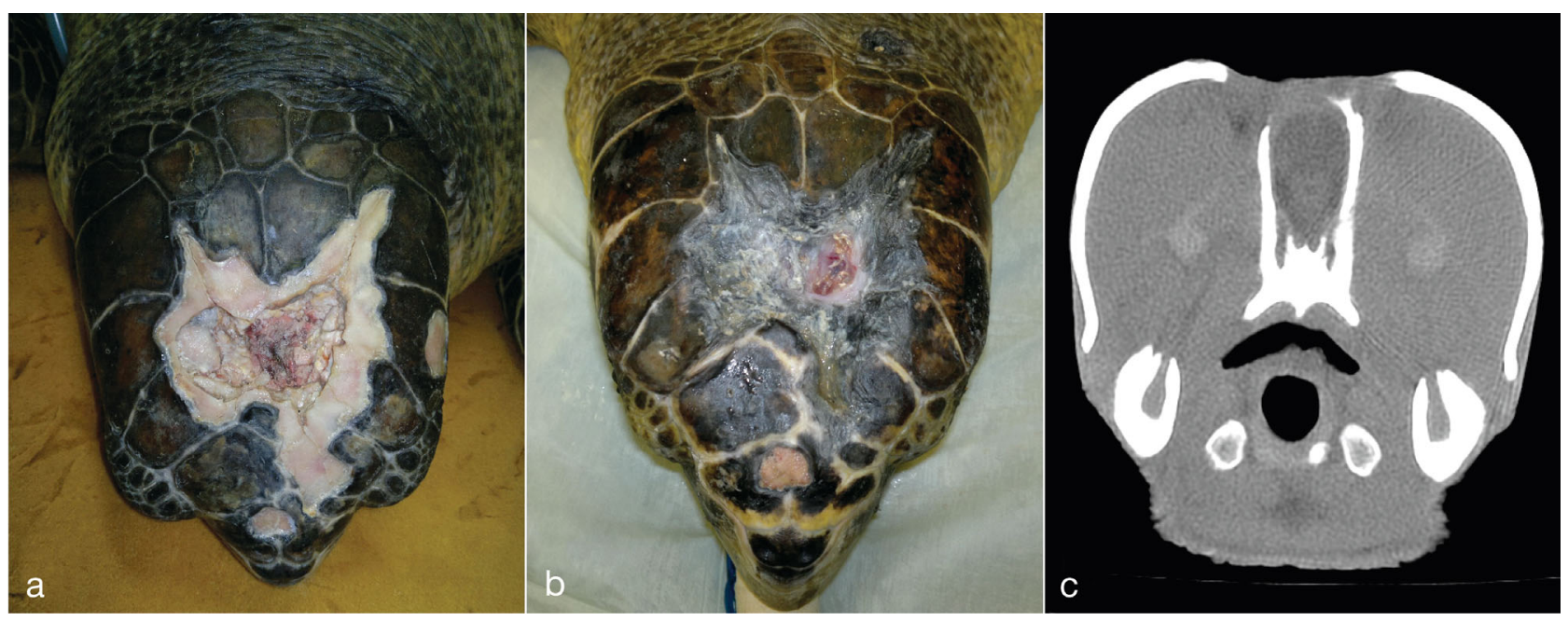

Fig. 4. Turtle B. Appearance of the wound (a) on Day 1 on arrival at the clinic before surgical curettage and (b) on Day 30 after the surgical curettage. (c) Transverse image from the computed tomography scan (brain algorithm: window width 40, window level 400) performed once the wound healed 
was $0.087 \mathrm{~cm} \mathrm{~d}^{-1}$ in Turtle A, $0.066 \mathrm{~cm} \mathrm{~d}^{-1}$ in Turtle B and $0.059 \mathrm{~cm} \mathrm{~d}^{-1}$ in Turtle C. Granulation tissue appeared within a few days of treatment.

None of the turtles developed local infection or sepsis, and no wound exhibited clinical evidence of superficial or deep infection.

No turtle showed signs of adverse reactions, and no side effects were observed.

The animals resumed their normal appetite and ability to feed $61 \pm 22 \mathrm{~d}$ (range $44-93 \mathrm{~d}$ ) after insertion of the feeding tube, allowing the tube to be removed.

All 3 turtles were successfully released in the wild after a period of rehabilitation in rescue centers.

\section{DISCUSSION}

The turtles in this study had a fairly common type of trauma. The cause of such extensive and skulldeep injuries is in some cases attributable to incidental impact with motor boat propellers and/or hulls; more often, the cause is interaction with fishermen who, after accidentally trapping animals in fishing nets, hit them and then throw them-presumed dead - into the sea (Lutcavage et al. 1997). Animals affected by this type of trauma are usually found either dead or in critical condition, and without veterinary intervention, death inevitably ensues.

In chelonian medicine, vacuum-assisted closure (VAC) therapy is used to treat challenging wounds involving carapace and plastron defects and tissue exposure, most often caused by trauma and less frequently by thermal burns or infection. However, negative pressure should not be used directly over exposed lungs or other organs, blood vessel or nerves (Mader \& Divers 2013), and hence we did not use VAC as part of our treatment regimen.

To date, there are no recommended therapies for severe lesions with exposure of the brain tissue. Euthanasia often appears to be the most ethical choice if it is not possible to avoid animal pain, but appropriate treatment can increase life expectancy and may minimize brain injuries (Goldberg et al. 2010).

During anesthesia, the passive respiratory rate used was higher than that already described (Chittick et al. 2002). We decided to use a higher respiratory rate to cause a transitory hypocapnia to decrease the cerebral blood flow (Söderström et al. 1997) and consequently reduce the brain bulk, facilitating intracranial surgery, and the acute brain swelling.

The plant-derived dressing 1 Primary Wound Dressing ${ }^{\circledR}$ has been shown to have a marked capa- city to promote re-epithelialization and wound healing in mammals, even in cases that are very difficult to manage (Läuchli et al. 2012, Carnevali et al. 2014). The wounds $(n=3)$ were fully epithelialized after about $10 \mathrm{wk}$ of treatment. Only 1 additional curettage surgery was needed (Turtle A), and no clinical evidence of superficial or deep infection was observed, despite the fact that the hospitalization tanks were obviously a contaminated environment.

This outcome may also be explained by the antimicrobial activity of the fatty acids contained in the spray (Desbois \& Smith 2010) and the balanced moist environment obtained by the semi-occlusive layer created by the oil (Sharman 2003). Therefore, cell proliferation is activated, and despite the moist environment, the bacterial load remains under control.

Daily dressing was easy and quick to apply, and the animals showed little or no reaction during the first dressings, and after only 2 to 3 medications, no reaction at all was elicited. The healing time of the skull wounds, ranging between 66 and $85 \mathrm{~d}$, showed a proliferation rate of $0.07 \mathrm{~cm} \mathrm{~d}^{-1}$.

In human medicine, the treatment of scalp wounds with exposed bone is very challenging, particularly when the periosteum is exposed (Snow et al. 1994, Läuchli et al. 2012). In a retrospective study, the plant-derived dressing 1 Primary Wound Dressing ${ }^{\circledR}$ was an effective therapy for the treatment of scalp wounds with exposed bone. The time to complete healing by secondary intention was 4 to $20 \mathrm{wk}$, with a proliferation rate of $0.107 \mathrm{~cm} \mathrm{~d}^{-1}$ (Läuchli et al. 2012).

Reptiles heal more slowly than do mammals, with the rate of healing in reptiles being temperature dependent (Smith \& Barker 1988). Moreover, reptile wound healing differs from that of mammals in that granulation tissue production is rare, and epithelial migration occurs beneath either a proteinaceous crust or necrotic epidermal and dermal tissue (Keller et al. 2014). A study by Smith \& Barker (1988) evaluating the effects of various topical dressings on experimental wounds on snakes showed that occlusive polyurethane film produced the best results, while topical antibiotic powder and ointment appeared to slow the healing response.

A treatment protocol for wounds should ideally prevent contamination and dehydration, remove exudate, prevent infections, promote wound healing, be easy to apply and remove, and be comfortable. The association of the dressing with the use of Vaseline-soaked gauze was effective to seal the wound, allowing us to hospitalize the turtles in water. This secondary dressing was an effective means of isolat- 
ing the wound bed from contact with water during the healing process.

Neurological examinations performed during and after treatment showed no change compared with the initial examination, nor was any systemic reaction due to absorption of the drug observed during treatment. Furthermore, Turtle A recovered from neurological deficits after the rehabilitation period in a rescue center (about $10 \mathrm{mo}$ ).

In addition to causing pain, many disinfectants/ antimicrobials used to control microbial contamination/infection of the wound bed also have cytotoxic effects that prevent or delay healing (Niedner 1997, Hidalgo \& Dominguez 2001, Drosou et al. 2003, Wilson et al. 2005, Banwell 2006). The present treatment protocol for wounds supported each phase of the healing process, avoiding the need to use cytotoxic disinfectants (Noble \& Kent 1992, Lloyd et al. 1999, Rantala et al. 2004, Paterson et al. 2005, Lee et al. 2006).

\section{CONCLUSIONS}

Hundreds of injured turtles are rescued and treated annually in rescue centers. With extensive rehabilitation efforts, many injured turtles are eventually returned to the wild; in fact, sea turtles have been shown to have an astonishing capability to heal, given proper supportive care and husbandry (Mader \& Divers 2013).

Injured animals presenting serious lesions of the skull similar to those treated in the present study are not uncommon, hence the need to develop a suitable protocol for managing these complicated cases. The initial lesions were extremely severe, but the clinical course was of excellent quality, and the sea turtles underwent a rapid, complete recovery, free from complications. A scar tissue without defects finally developed, allowing the 3 loggerheads to be released back into the sea.

There are some limitations to the study presented here. Our uncontrolled study was conducted on a small sample of individuals, and it will be necessary to test the protocol in a larger series before it can be definitively declared safe. This study also lacks a control group, and since no investigations on the treatment of head injury with brain exposure are available in international literature, the effectiveness of protocols herein employed cannot be compared. Nevertheless, in this early experience, the absence of adverse reactions to the plant-derived dressing 1 Primary Wound Dressing ${ }^{\circledR}$ allows us to consider the potential applicability of the present treatment protocol in sea turtle traumatic injuries of the skull with brain tissue exposure.

Turtles with severe head trauma run a serious risk of death or permanent brain damage. For this reason, early diagnosis and appropriate treatment improve prognosis and may minimize brain injuries.

\section{LITERATURE CITED}

Banwell H (2006) What is the evidence for tissue regeneration impairment when using a formulation of PVP-I antiseptic on open wounds? Dermatology 212:66-76

Camacho M, Quintana MDP, Calabuig P, Luzardo OP, Boada LD, Zumbado M, Orós J (2015) Acid-base and plasma biochemical changes using crystalloid fluids in stranded juvenile loggerhead sea turtles (Caretta caretta). PLoS ONE 10:e0132217

Carnevali F, Argentieri M, Ippedico G, Minniti CA, Amodio L, Mellano L, van der Esch SA (2014) Managing horse wounds either presenting or not with exuberant granulation tissue using an innovative wound dressing: a retrospective non-controlled study. J Anim Vet Sci 1:6-16

Chittick EJ, Stamper MA, Beasley JFE, Lewbart GA, Horne WA (2002) Medetomidine, ketamine, and sevoflurane for anesthesia of injured loggerhead sea turtles: 13 cases (1996-2000). J Am Vet Med Assoc 221:1019-1025

Desbois AP, Smith VJ (2010) Antibacterial free fatty acids: activities, mechanisms of action and biotechnological potential. Appl Microbiol Biotechnol 85:1629-1642

> Di Bello A, Valastro C, Freggi D, Saponaro V, Grimaldi D (2010) Ultrasound-guided vascular catheterization in loggerhead sea turtles (Caretta caretta). J Zoo Wildl Med 41:516-518

Di Bello A, Valastro C, Freggi D, Lai OR, Soloperto S, Crescenzo G (2011) The use of oesophagostomy tube for the force-feeding in sea turtles. In: Jones TT, Wallace BP (compilers) Proc 31st Ann Symp Sea Turtle Biol Conserv. NOAA Tech Mem NMFS-SEFSC-631, p 187

Drosou A, Falabella A, Kirsner RS (2003) Antiseptics on wounds: an area of controversy. Wounds 15:149-166

Goldberg DW, Adeodato A, Almeida DT, Corrêa LG (2010) Green turtle head trauma with intracerebral hemorrhage: image diagnosis and treatment. Cienc Rural 40:2402-2405

Hidalgo E, Dominguez C (2001) Mechanisms underlying chlorhexidine-induced cytotoxicity. Toxicol In Vitro 15: 271-276

> Keller KA, Paul-Murphy J, Weber EPS III, Kass PH and others (2014) Assessment of platelet-derived growth factor using a splinted full thickness dermal wound model in bearded dragons (Pogona vitticeps). J Zoo Wildl Med 45: 866-874

Läuchli S (2012) 1 Primary Wound Dressing ${ }^{\circledR}$ : clinical experience. Hosp Health Eur 2012

Läuchli S, Hafner J, Wehrmann C, French LE, Hunziker $T$ (2012) Post-surgical scalp wounds with exposed bone treated with a plant-derived wound therapeutic. J Wound Care 21:228-233

> Lee SY, Kotapati S, Kuti JL, Nightingale CH, Nicolau DP (2006) Impact of extended-spectrum beta-lactamaseproducing Escherichia coli and Klebsiella species on clinical outcomes and hospital costs: a matched cohort study. Infect Control Hosp Epidemiol 27:1226-1232 
Lloyd DH, Lamport AI, Noble WC, Howell SA (1999) Fluoroquinolone resistance in Staphylococcus intermedius. Vet Dermatol 10:249-251

Lutcavage ME, Plotkin P, Witherington B, Lutz PL (1997). Human impacts on sea turtle survival. In: Lutz PL, Musick JA (eds) The biology of sea turtles, Vol 1. CRC Press, Boca Raton, FL, p 387- 409

Mader DR, Divers SJ (eds) (2013) Current therapy in reptile medicine and surgery, 1st edn. Saunders, St. Louis, MO

Mainetti S, Carnevali F (2013) An experience with paediatric burn wounds treated with a plant-derived wound therapeutic. J Wound Care 22:681-689

McArthur S, Meyer J, Innis C (2004) Anatomy and physiology. In: McArthur S, Wilkinson R, Meyer J (eds) Medicine and surgery of tortoises and turtles. Blackwell, Oxford, p 35-71

Mitchell MA, Diaz-Figueroa O (2004) Wound management in reptiles. Vet Clin North Am Exot Anim Pract 7: 123-140

Naganobu K, Ogawa H, Oyadomari N, Sugimoto M (2000) Surgical repair of a depressed fracture in a green sea turtle, Chelonia mydas. J Vet Med Sci 62:103-104

Niedner R (1997) Cytotoxicity and sensitization of povidonelodine and other frequently used anti-infective agents. Dermatology 195:89-92

Noble WC, Kent LE (1992) Antibiotic resistance in Staphylococcus intermedius isolated from cases of pyoderma in the dog. Vet Dermatol 3:71-74

Oertel M, Kelly DF, McArthur D, Boscardin WJ and others (2002) Progressive hemorrhage after head trauma: predictors and consequences of the evolving injury. J Neurosurg 96:109-116

Orós J, Torrent A, Calabuig P, Déniz S (2005) Diseases and causes of mortality among sea turtles stranded in the Canary Islands, Spain (1998-2001). Dis Aquat Org 63: $13-24$

Editorial responsibility: Alex Hyatt,

Geelong, Victoria, Australia
Paterson DL, Rossi F, Baquero F, Hsueh PR and others (2005) In vitro susceptibilities of aerobic and facultative Gramnegative bacilli isolated from patients with intra-abdominal infections worldwide: the 2003 study for monitoring antimicrobial resistance trends (SMART). J Antimicrob Chemother 55:965-973

> Rantala M, Lahti E, Kuhalampi J, Pesonen S, Järvinen AK, Saijonmaa-Koulumies L, Honkanen-Buzalski T (2004) Antimicrobial resistance in Staphylococcus spp., Escherichia coli and Enterococcus spp. in dogs given antibiotics for chronic dermatological disorders, compared with non-treated control dogs. Acta Vet Scand 45:37-45

Rinaldi S, Iannaccone M, Magi GE, Costantini E and others (2013) Physical reparative treatment in reptiles. BMC Vet Res 9:39

Sharman D (2003) Moist wound healing: a review of evidence, application and outcome. Diabetic Foot 6:112-120

Smith DA, Barker IK (1988) Healing of cutaneous wounds in the common garter snake (Thamnophis sirtalis). Can J Vet Res 52:111-119

Snow SN, Stiff MA, Bullen R, Mohs FE, Chao WH (1994) Second-intention healing of exposed facial-scalp bone after Mohs surgery for skin cancer: review of ninety-one cases. J Am Acad Dermatol 31:450-454

Söderström V, Nilsson GE, Lutz PL (1997) Effects of inhibition of nitric oxide synthesis and of hypercapnia on blood pressure and brain blood flow in the turtle. J Exp Biol 200:815-820

van der Esch SA, Carnevali F, Cristofaro M (2007) Mix 557: a topical remedy with repellent, biocidal and healing properties for treating myiasis both in mammal as in human. Proc 17th EWMA Conf, 2-4 May, Glasgow

Wilson JR, Mills JG, Prather ID, Dimitrijevich SD (2005) A toxicity index of skin and wound cleansers used on in vitro fibroblasts and keratinocytes. Adv Skin Wound Care 18:373-378

Submitted: July 28, 2015; Accepted: February 21, 2016 Proofs received from author(s): April 12, 2016 